\title{
Aposentadoria e planejamento para vida pós-trabalho: um estudo com servidores de um Instituto Federal de Educação
}

\author{
Retirement and planning for post-work life: a study with civil servants from a Federal Institute of \\ Education
}

Maria de Fátima Carvalho Carneiro' $\mathbb{1}$ Vicente Paulo Alves ${ }^{2} \mathbb{D}$ Henrique Salmazo da Silva² ${ }^{\mathbb{D}}$

\section{Resumo}

Objetivo: Investigar fatores associados à construção de projeto de vida pós-trabalho em servidores do Instituto Federal do Tocantins e verificar temas de interesse para elaboração de um Programa de Preparação para a Aposentadoria. Método: Tratou-se de um estudo exploratório, de natureza quantitativa e de corte transversal. Foram entrevistados 94 servidores dentre técnicos administrativos e docentes, que estavam com 5, 10 e 15 anos para se aposentarem. Os participantes foram avaliados por meio de questionário sociodemográfico, QWLQbref questionário de avaliação da qualidade de vida no trabalho (QVT) e Escala dos Fatores-Chave de Planejamento para a Aposentadoria (KFRP). Resultados: Houve correlações estatisticamente significantes e positivas entre o subdomínio psicológico de QVT e o Fator Risco ou Sobrevivência, e entre o domínio profissional de QVT e o Fator Relacionamentos Familiares. O grupo de profissionais com 5 a 10 anos para se aposentar apresentou a maior média no domínio psicológico de QVT $(p=0,039)$. Participantes do sexo feminino focalizaram mais o novo começo profissional do que os homens ( $p=0,023)$, e participantes sem companheiro(a) apresentaram menor pontuação no item relacionamento familiar como fator de planejamento pós-aposentadoria $(p=0,027)$. Das temáticas para o Planejamento de Programa para Aposentadoria, destacaramse: planejamento financeiro (13\%), legislação específica sobre aposentadoria (11\%), e entretenimento e qualidade de vida (7\%). Conclusão: O planejamento para aposentadoria associou-se a qualidade de vida relacionada ao trabalho, sexo e estado conjugal. Essas variáveis, em conjunto com as temáticas propostas pelos servidores, podem contribuir para o planejamento de um Programa de Preparação para a Aposentadoria.

\footnotetext{
Instituto Federal de Educação, Ciência e Tecnologia do Tocantins (IFTO), Diretoria de Gestão de Pessoas Palmas, TO, Brasil.

2 Universidade Católica de Brasília (UCB), Programa de Pós-graduação em Gerontologia. Brasília, DF, Brasil.

Os autores declaram não haver conflito na concepção deste trabalho.

Não houve financiamento para a execução deste trabalho.

Palavras-chave:

Aposentadoria. Projeto de Vida. Programas de Preparação para a Aposentadoria. 


\section{Abstract}

Objective: To investigate factors associated with creating a post-work life project with workers from the Federal Institute of Tocantins, and check topics of interest to create a Retirement Preparation Program. Method: This was an exploratory, quantitative, and cross-sectional study. The respondents were 94 civil servants among administrative technicians and scholars who would retire in 5,10 and 15 years. Participants were assessed using a sociodemographic questionnaire - the QWLQbref questionnaire - to assess the quality of work life (QWL), and the Key Factors for Retirement Planning (KFRP)

Scale. Results: There were statistically significant and positive correlations between the psychological subdomain of QWL and the Risk Factor or Survival, and between the professional domain of QWL and the Family Relationships Factor. The group of professionals to be retired in 5 to 10 years had the highest average in the psychological domain of QWL ( $p=0.039)$. Female participants focused more on the new professional beginning than men $(p=0.023)$, and participants without a partner had a lower score in the item 'family relationship' as a post-retirement planning factor $(p=0.027)$. Among the topics for the Planning of the Retirement Program, the following stand out: financial planning (13\%), specific legislation on retirement (11\%), and entertainment and quality of life (7\%). Conclusion: Retirement planning was associated with the quality of life related to work, gender, and marital status. These variables together with the topics proposed by the servants can contribute to the planning of a Retirement Preparation Program.

Keywords: Retirement. Life Project. Retirement Preparation Programs.

\section{INTRODUÇÃO}

Em face do acelerado processo de envelhecimento observado no Brasil, a aposentadoria é um dos temas mais debatidos no cenário político e econômico do país. Diante deste contexto, Fagnani ${ }^{1}$ declara que a mais recente reforma da previdência prolonga o acesso do trabalhador aos benefícios previdenciários e, diante dessa condição, cabe refletir em Boehs et $a .^{2}$ o papel que o trabalho desempenha na vida das pessoas, pois, por meio de sua ação, ocorre a intermediação das relações do homem com o meio.

Assim, para Corrêa ${ }^{3}$ e Albornoz ${ }^{4}$ o trabalho tem significado existencial e seu provento satisfaz necessidades humanas fundamentais de sustento e satisfação. Com isso, o trabalho é condição preponderante para a realização humana, pois possibilita ação transformadora sobre a natureza e a si mesmo, contribuindo para a sobrevivência e para realização pessoal.

No universo das discussões sobre aposentadoria, o conceito pós-trabalho aparece com frequência, contudo, é um tema ainda escasso na literatura. Apesar disso, no dicionário on-line de português ${ }^{5}$, a origem da palavra "pós" vem do latim post, depois. Ou seja, é um termo "que dá a ideia do que é posterior, do que ocorre após, no espaço e no tempo". Desta forma, entende-se que se trata de um período subsequente ao trabalho.

De acordo com Fagnani ${ }^{1}$, o tema da aposentadoria foi tratado recentemente em uma reforma previdenciária, decorrente da Proposta de Emenda Constitucional conhecida como PEC 287/16, que culminou em acréscimo da idade mínima somado ao tempo de contribuição; regras de transição que fixaram mais tempo para se aposentar e mudanças nas alíquotas de desconto do INSS.

Dessa forma, Fagnani ${ }^{1}$ ratfica que a nova previdência irá manter o trabalhador por mais tempo nas organizações de trabalho, ou seja, os trabalhadores irão envelhecer no trabalho, exatamente a fase da vida em que se está mais suscetível aos eventos não normativos que afetam o bem-estar e a qualidade de vida do indivíduo, além da redução do desempenho funcional e da eficiência do organismo em responder a estressores ambientais. Nascimento e Polia ${ }^{6}$ entendem que, desse debate, ocorrerá "impacto diretamente nos projetos presentes e futuros de quem está próximo do período de aposentadoria". 
Tendo como base esse pressuposto, para Soares et al. $^{7}$ é possível dizer que a transição para a vida pós-trabalho exige planejamento. Para isso, pode-se propor a implementação de Programas de Preparação para Aposentadoria (PPA). Nesse discurso, o estudo de Menezes e França ${ }^{8}$ demonstrou que planejar com antecedência também é requisito fundamental para uma aposentadoria bem-sucedida, pois, além de promover atitudes positivas, aumenta a satisfação com a aposentadoria: a autonomia, reconhecimentos de direitos, segurança, dignidade, bem-estar e saúde; em comparação aos que não se planejaram.

Rafalski e Andrade ratificam que o órgão o qual dispõe de um serviço de preparação para a aposentadoria influencia significativamente $o$ planejamento nas dimensões financeira, social e emocional.

Para delinear um Programa de Preparação para a Aposentadoria, é imprescindível conhecer sobre o tema e, principalmente, os anseios e necessidades dos trabalhadores que serão o público desses programas. Assim, na literatura especializada sobre fatores-chave para o planejamento da aposentadoria, Froidevaux ${ }^{10}$, França e Hershey ${ }^{11}$ observaram que o planejamento deve ser direcionado para questões como: investimento financeiro, planejamento e vínculo familiar, planejamento em saúde, atividades de lazer, manutenção da rede social, atividade voluntária, mudança no estilo de vida, e aposentadoria voluntária.

Face ao planejamento da aposentadoria, o estudo de Cheremeta et al. ${ }^{12}$ destaca alguns fatores como satisfação com o trabalho e qualidade de vida no trabalho são aspectos que podem influenciar a saída ou a permanência na organização.

Neste sentido, o presente estudo objetivou investigar fatores associados à construção de projeto de vida pós-trabalho em servidores do Instituto Federal do Tocantins, e verificar temas de interesse para elaboração de um Programa de Preparação para a Aposentadoria.

\section{MÉTODO}

Tratou-se de um estudo exploratório, de natureza quantitativa, de corte transversal, que foi desenvolvido por meio do estudo de campo. Participaram do estudo, de forma voluntária, servidores técnicos administrativos e docentes do quadro efetivo e ativo do Instituto Federal do Tocantins (IFTO), Brasil.

A seleção da amostra foi feita por meio de um extrato de dados funcionais do servidor, como idade e tempo de serviço fornecidos pela Diretoria de Gestão de Pessoas do IFTO, mediante pesquisa no sistema SIAPE (Sistema Integrado de Administração de Recursos Humanos) da Administração Pública Federal.

Os critérios de inclusão da amostra foram: servidores que estavam a 5, 10 e 15 anos para se aposentar; que estavam aptos para as funções designadas ao cargo que ocupavam; com disponibilidade para responder aos questionários. Foram excluídas da amostra servidores que apresentavam problemas de comunicação e de linguagem; com diagnóstico de depressão e/ou de doenças ocupacionais sem tratamento; aposentado em outra função; em cooperação técnica, requisitados, em exercício provisório e substituto.

A amostra consistiu no recrutamento de 94 servidores que se enquadravam nos critérios de seleção mencionados da população total de 124 servidores. Para cálculo amostral utilizou-se a fórmula para tamanho da amostra para populações finitas. O cálculo do tamanho da amostra considerou um grau de confiança de $95 \%$ e erro de $5 \%$, p valor igual ou inferior a 0,05 . Os participantes que consentiram em participar da pesquisa foram convidados a assinar o Termo de Consentimento Livre e Esclarecido (TCLE) e posteriormente a responder os questionários do estudo.

No presente estudo, foram utilizados os seguintes instrumentos avaliativos: questionário sociodemográfico, composto por 11 questões referentes à caracterização dos participantes, como, idade, estado civil, sexo, escolaridade, renda, vínculo com a instituição, tipo de carreira, campus de exercício, expectativa para se aposentar, e de programas de preparação para a aposentadoria;questionário de avaliação da qualidade de vida no trabalho (QWLQbref), elaborado pelos pesquisadores Cheremeta et al. ${ }^{12}$, composto por 20 perguntas, que foram formuladas para uma escala do tipo Likert e 
organizadas em quatro domínios: pessoal, saúde, psicológico e profissional, seguindo os mesmos padrões estabelecidos no World Health Of Quality Of Lilfe-bref provindo do World Health OfQuality OfLilfe 100; e Escala dos Fatores-Chave de Planejamento para a Aposentadoria (KFRP, do inglês Key Factors on Retirement Planning). Esta escala foi adaptada para categorias profissionais não gerenciais por França e Carneiro $^{13}$, a partir da escala original criada em 2008 para executivos brasileiros e neozelandeses sobre atitudes frente à aposentadoria. Essa versão adaptada contém 15 itens, divididos em quatro dimensões que avaliam: fatores de bem-estar pessoal, fatores de risco ou de sobrevivência, novo começo profissional e relacionamentos familiares.

O estudo foi realizado no Campus Palmas e Reitoria do IFTO, localizados na cidade de Palmas, Tocantins, estado que está localizado na Região Norte do Brasil. O período de aplicação dos instrumentos de coleta ocorreu nos meses de janeiro a fevereiro de 2020.

Os servidores docentes selecionados foram convidados a participarem do estudo por e-mail institucional, onde foram agendados dois encontros em duas salas de professores do próprio Campus, para o preenchimento dos questionários. Posteriormente, os que não compareceram foram abordados individualmente em suas salas para o preenchimento. O mesmo ocorreu com os técnicos administrativos, recrutados individualmente. Quanto aos servidores da reitoria, esses foram recrutados de forma individual.

Os dados foram analisados de forma quantitativa e por meio de testes estatísticos. Inicialmente, os dados foram descritos por meio de média, desvio-padrão e frequência. Posteriormente, avaliada a normalidade das variáveis pelo teste de Shapiro-Wilkis e eleito o tipo de análise (paramétrica ou não paramétrica) para comparação entre grupos. O nível de significância utilizado nas análises foi de 5\%, ou $p>0,05$.
Este estudo foi aprovado pelo Comitê de Ética em Pesquisa com Seres Humanos no âmbito das ciências humanas da Universidade Católica de Brasília -UCB, sob o número do protocolo 18145319.3.0000.0029, e todos os participantes assinaram o TCLE.

\section{RESULTADOS}

Conforme Tabela 1 observa-se que a maioria da população foi composta por profissionais com faixa etária de 50 a 55 anos, casados, com nível de escolaridade mestrado, faixa de renda entre 8 e 11 salários mínimos, carreira docente, com até 15 anos para se aposentar e Muito ou Muitíssimo preocupados com a aposentadoria. Quase metade da população foi composta por profissionais do sexo masculino e menos da metade dos participantes referiram conhecer do que se tratava um Programa de Preparação para Aposentadoria.

$\mathrm{Na}$ amostra em geral, houve maior pontuação do domínio psicológico de qualidade de vida no trabalho, seguido do domínio pessoal, físico e profissional (Tabela 2). Neste contexto, o trabalho pode se associar ao bem-estar e satisfação pessoal. No que se refere aos domínios dos Fatores-Chave para o Planejamento da Aposentadoria, os participantes atribuíram maior importância aos domínios Risco ou Sobrevivência, seguido por Relacionamentos Familiares, Bem-estarpessoal e social e Novo começo profissional. Nesse contexto, os dados sugerem que, no que se refere ao planejamento para a aposentadoria, houve maior importância com questões relativas aos investimentos financeiros, desenvolvimento intelectual, promoção de saúde e alimentação saudável, que compõem o domínio Risco ou Sobrevivência, seguidos dos relacionamentos com o parceiro, filhos e pais que compõem o domínio Relacionamentos Familiares. É possível que a baixa pontuação no domínio Novo começo profissional indique que a amostra investigada não pretende se engajar em outras atividades profissionais pós-aposentadoria. 
Tabela 1. Caracterização sociodemográfica dos servidores do IFTO (N=94), Palmas, TO, 2020.

\begin{tabular}{|c|c|}
\hline Variáveis & $\mathrm{n}(\%)$ \\
\hline \multicolumn{2}{|l|}{ Sexo } \\
\hline Feminino & $46(48,9)$ \\
\hline Masculino & $48(51,1)$ \\
\hline \multicolumn{2}{|l|}{ Faixa Etária (em anos) } \\
\hline 45 a 50 & $35(37,2)$ \\
\hline 50 a 55 & $38(40,4)$ \\
\hline 55 a 60 & $12(12,8)$ \\
\hline$>60$ & $9(9,6)$ \\
\hline \multicolumn{2}{|l|}{ Estado Civil } \\
\hline Solteiro(a) & $16(17)$ \\
\hline Casado(a) & $64(68,1)$ \\
\hline Divorciado(a) & $9(9,6)$ \\
\hline Viúvo(a) & $0(0,0)$ \\
\hline Relação estável & $5(5,3)$ \\
\hline \multicolumn{2}{|l|}{ Escolaridade } \\
\hline Superior & $4(4,3)$ \\
\hline Pós-graduação & $24(25,5)$ \\
\hline Mestrado & $32(34)$ \\
\hline Mestrado incompleto & $10(10,6)$ \\
\hline Doutorado & $20(21,3)$ \\
\hline Doutorado incompleto & $2(2,1)$ \\
\hline Ensino Médio & $1(1,1)$ \\
\hline Pós-doutorado & $1(1,1)$ \\
\hline \multicolumn{2}{|c|}{ Renda (em salários mínimos) } \\
\hline 3 a 5 & $13(13,8)$ \\
\hline 5 a 8 & $23(24,5)$ \\
\hline 8 a 11 & $41(43,6)$ \\
\hline$>11$ & $17(18,1)$ \\
\hline \multicolumn{2}{|l|}{ Tipo de Carreira } \\
\hline Técnico & $29(30,9)$ \\
\hline Docente & $65(69,1)$ \\
\hline \multicolumn{2}{|l|}{ Exercício } \\
\hline Reitoria & $8(8,5)$ \\
\hline Campus Palmas & $86(91,5)$ \\
\hline \multicolumn{2}{|c|}{ Expectativa para se aposentar } \\
\hline Abono & $7(7,4)$ \\
\hline Até 5 anos & $12(12,8)$ \\
\hline Até 10 anos & $14(14,9)$ \\
\hline Até 15 anos & $61(64,9)$ \\
\hline \multicolumn{2}{|c|}{ Já ouviu falar de programa de Preparação para Aposentadoria } \\
\hline Sim & $42(44,7)$ \\
\hline Não & $52(55,3)$ \\
\hline
\end{tabular}


Continuação da Tabela 1

\begin{tabular}{ll}
\hline Variáveis & $\mathrm{n}(\%)$ \\
\hline Preocupado & \\
Nenhum pouco & $11(11,7)$ \\
Muito pouco & $8(8,5)$ \\
Mais ou menos & $23(24,5)$ \\
Muito & $29(30,9)$ \\
Muitíssimo & $23(24,5)$ \\
\hline
\end{tabular}

Tabela 2. Pontuação nos domínios de Qualidade de Vida no Trabalho e Fatores-Chave para o Planejamento da Aposentadoria entre os servidores do IFTO (N=94), Palmas, TO, 2020.

\begin{tabular}{lcc}
\hline Pontuação nas escalas & Média (DP) & Min-Max \\
\hline Qualidade de Vida Relacionada ao Trabalho & & \\
Físico & $3,63( \pm 0,55)$ & $2,00-4,00$ \\
Psicológico & $4,04( \pm 0,67)$ & $2,00-5,00$ \\
Pessoal & $4,01( \pm 0,56)$ & $2,00-5,00$ \\
Profissional & $3,62( \pm 0,57)$ & $2,00-5,00$ \\
\hline Fatores-chave para o Planejamento da Aposentadoria & & \\
Bem estar pessoal e social & $3,03( \pm 0,61)$ & $1,50-4,00$ \\
Risco ou sobrevivencia & $3,38( \pm 0,63)$ & $1,00-4,00$ \\
Novo comeco profissional & $2,80( \pm 0,61)$ & $1,00-4,00$ \\
Relacionamentos familiares & $3,36( \pm 0,90)$ & $1,00-4,00$ \\
\hline
\end{tabular}

DP: Desvio Padrão; Min: Mínimo; Max: Máximo.

Conforme Tabela 3, houve correlações estatisticamente significantes e positivas entre o subdomínio psicológico de QVT e o Fator Risco on Sobrevivência (Coeficiente de correlação de Spearman: $\mathrm{r}=0,209 ; p>0,05)$, e entre o domínio profissional de QVT e o Fator Relacionamentos Familiares (Coeficiente de correlação de Spearman: $r=0,215, p>0,05)$. Ou seja, quanto maior a relevância do domínio psicológico de qualidade de vida, mais os participantes valorizaram o Fator Risco on Sobrevivência como um atributo importante como fator chave para o planejamento da aposentadoria, o mesmo ocorreu entre o domínio profissional de qualidade de vida relacionada ao trabalho e Fator Relacionamentos Familiares. Em ambos os instrumentos de avaliação, houve associações positivas entre os subdomínios.
No que se refere à relação entre expectativa para se aposentar, o grupo com 5 a até 10 anos para se aposentar apresentou a maior média no domínio psicológico de Qualidade de Vida no Trabalho $(p=0,039)$ e houve tendência do grupo com abono permanência a apresentar maior pontuação no domínio pessoal ( $p=0,076$ ) (Tabela 3). É possível que a função do trabalho nos grupos mais próximos para se aposentar possa ter mediado essas associações, subsidiado por mecanismos de comparação social, escolha, engajamento pessoal e inserção social. Outra hipótese refere a maior habilidade social desse grupo em lidar com os estressores relacionados ao trabalho. No que se refere à preocupação com relação à aposentadoria, o grupo Muito pouco preocupado e Muito preocupado apresentou as menores pontuações nos fatores bem-estar pessoal e social (Tabela 4). 
Tabela 3. Qualidade de Vida Relacionada ao Trabalho conforme expectativas para se aposentar e variáveis sociodemográficas de servidores do IFTO (N=94), Palmas, TO, 2020.

\begin{tabular}{|c|c|c|c|c|c|c|c|c|}
\hline \multirow[b]{2}{*}{$\begin{array}{l}\text { Expectativa para se } \\
\text { aposentar e Variáveis } \\
\text { sociodemográficas }\end{array}$} & \multicolumn{8}{|c|}{ Qualidade de Vida Relacionada ao trabalho } \\
\hline & $\begin{array}{l}\text { Físico } \\
\text { M (DP) }\end{array}$ & p valor & $\begin{array}{l}\text { Psicológico } \\
\text { M (DP) }\end{array}$ & p valor & $\begin{array}{l}\text { Pessoal } \\
\text { M (DP) }\end{array}$ & p valor & $\begin{array}{l}\text { Profissional } \\
\text { M (DP) }\end{array}$ & p valor \\
\hline \multicolumn{9}{|l|}{$\begin{array}{l}\text { Expectativa para se } \\
\text { aposentar }\end{array}$} \\
\hline Abono & $3,86( \pm 0,38)$ & 0,387 & $4,14( \pm 0,69)$ & 0,039 & $4,43( \pm 0,53)$ & 0,076 & $3,71( \pm 0,49)$ & 0,173 \\
\hline 5 a 10 anos & $3,69( \pm 0,47)$ & & $4,31( \pm 0,68)$ & & $3,92( \pm 0,56)$ & & $3,77( \pm 0,59)$ & \\
\hline Até 15 anos & $3,57( \pm 0,59)$ & & $3,92( \pm 0,64)^{*}$ & & $4,00( \pm 0,55)$ & & $3,54( \pm 0,56)$ & \\
\hline \multicolumn{9}{|l|}{$\begin{array}{l}\text { Faixa Etária (em } \\
\text { anos) }\end{array}$} \\
\hline 45 a 50 & $3,57( \pm 0,61)$ & 0,516 & $4,03( \pm 0,71)$ & 0,557 & $4,03( \pm 0,45)$ & 0,244 & $3,60( \pm 0,55)$ & 0,793 \\
\hline 50 a 55 & $3,71( \pm 0,52)$ & & $4,00( \pm 0,57)$ & & $3,97( \pm 0,54)$ & & $3,68( \pm 0,57)$ & \\
\hline 55 a 60 & $3,50( \pm 0,52)$ & & $4,00( \pm 0,85)$ & & $3,83( \pm 0,83)$ & & $3,50( \pm 0,67)$ & \\
\hline$\geq 60$ & $3,67( \pm 0,50)$ & & $4,33( \pm 0,71)$ & & $4,33( \pm 0,50)$ & & $3,56( \pm 0,53)$ & \\
\hline \multicolumn{9}{|l|}{$\begin{array}{l}\text { Renda (em salário } \\
\text { mínimo) }\end{array}$} \\
\hline 3 a 5 & $3,38( \pm 0,51)$ & 0,133 & $3,69( \pm 0,75)$ & 0,190 & $3,85( \pm 0,38)$ & 0,351 & $3,77( \pm 0,60)$ & 0,450 \\
\hline 5 a 8 & $3,57( \pm 0,66)$ & & $4,13( \pm 0,55)$ & & $4,00( \pm 0,67)$ & & $3,48( \pm 0,59)$ & \\
\hline 8 a 11 & $3,68( \pm 0,47)$ & & $4,05( \pm 0,67)$ & & $4,00( \pm 0,55)$ & & $3,66( \pm 0,57)$ & \\
\hline \multicolumn{9}{|l|}{ Sexo } \\
\hline Feminino & $3,63( \pm 0,57)$ & 0,844 & $4,04( \pm 0,59)$ & 0,884 & $4,07( \pm 0,57)$ & 0,296 & $3,67( \pm 0,52)$ & 0,317 \\
\hline Masculino & $3,63( \pm 0,53)$ & & $4,04( \pm 0,74)$ & & $3,96( \pm 0,54)$ & & $3,56( \pm 0,62)$ & \\
\hline \multicolumn{9}{|l|}{ Estado Civil } \\
\hline Sem companheiro & $3,38( \pm 0,72)$ & 0,089 & $4,06( \pm 0,57)$ & 0,959 & $3,88( \pm 0,81)$ & 0,415 & $3,62( \pm 0,72)$ & 0,934 \\
\hline Com companheiro & $3,68( \pm 0,50)$ & & $4,04( \pm 0,69)$ & & $4,04( \pm 0,50)$ & & $3,62( \pm 0,54)$ & \\
\hline \multicolumn{9}{|l|}{$\begin{array}{l}\text { Grau de } \\
\text { preocupação }\end{array}$} \\
\hline Nenhum Pouco & $3,55( \pm 0,69)$ & 0,760 & $4,18( \pm 0,75)$ & 0,670 & $4,09( \pm 0,55)$ & 0,760 & $3,75( \pm 0,65)$ & 0,961 \\
\hline Muito pouco & $3,75( \pm 0,46)$ & & $4,13( \pm 0,64)$ & & $4,13( \pm 0,35)$ & & $3,88( \pm 0,35)$ & \\
\hline Mais ou menos & $3,70( \pm 0,56)$ & & $3,91( \pm 0,51)$ & & $4,00( \pm 0,43)$ & & $3,61( \pm 0,50)$ & \\
\hline Muito & $3,66( \pm 0,48)$ & & $4,07( \pm 0,80)$ & & $4,00( \pm 0,53)$ & & $3,59( \pm 0,57)$ & \\
\hline Muitíssimo & $3,52( \pm 0,59)$ & & $4,04( \pm 0,64)$ & & $3,96( \pm 0,77)$ & & $3,52( \pm 0,67)$ & \\
\hline
\end{tabular}

* Até 15 anos para se aposentar $<5$ a 10 anos; 
Tabela 4. Fatores-Chave para Planejamento da Aposentadoria conforme expectativas para se aposentar e variáveis sociodemográficas de servidores do IFTO (N=94), Palmas, TO, 2020.

\begin{tabular}{|c|c|c|c|c|c|c|c|c|}
\hline \multirow[b]{2}{*}{$\begin{array}{l}\text { Expectativa para se } \\
\text { aposentar variáveis } \\
\text { sociodemográficas }\end{array}$} & \multirow[b]{2}{*}{$\begin{array}{l}\text { Bem estar } \\
\text { pessoal e } \\
\text { social }\end{array}$} & \multicolumn{6}{|c|}{ Fatores-Chave ao Planejamento da aposentadoria } & \multirow[b]{2}{*}{ p valor } \\
\hline & & pvalor & $\begin{array}{l}\text { Risco ou } \\
\text { sobrevivência }\end{array}$ & p valor & $\begin{array}{l}\text { Novo } \\
\text { começo } \\
\text { profissional }\end{array}$ & p valor & $\begin{array}{l}\text { Relacionamentos } \\
\text { familiares }\end{array}$ & \\
\hline \multicolumn{9}{|l|}{$\begin{array}{l}\text { Expectativa para se } \\
\text { aposentar* }\end{array}$} \\
\hline Abono & $2,88( \pm 0,37)$ & 0,432 & $3,50( \pm 0,29)$ & 0,678 & $2,81( \pm 0,63)$ & 0,857 & $3,43( \pm 0,84)$ & 0,977 \\
\hline 5 a 10 anos & $3,06( \pm 0,80)$ & & $3,18( \pm 0,87)$ & & $2,77( \pm 0,78)$ & & $3,25( \pm 1,13)$ & \\
\hline Até 15 anos & $3,03( \pm 0,55)$ & & $3,45( \pm 0,51)$ & & $2,82( \pm 0,53)$ & & $3,40( \pm 0,81)$ & \\
\hline \multicolumn{9}{|l|}{$\begin{array}{l}\text { Faixa Etária } \\
\text { (em anos) }\end{array}$} \\
\hline 45 a 50 & $2,91( \pm 0,63)$ & 0,642 & $3,36( \pm 0,68)$ & 0,844 & $2,80( \pm 0,64)$ & 0,967 & $3,36( \pm 0,86)$ & 0,937 \\
\hline 50 a 55 & $3,11( \pm 0,61)$ & & $3,42( \pm 0,63)$ & & $2,83( \pm 0,58)$ & & $3,39( \pm 0,91)$ & \\
\hline 55 a 60 & $3,06( \pm 0,64)$ & & $3,25( \pm 0,68)$ & & $2,69( \pm 0,66)$ & & $3,29( \pm 1,16)$ & \\
\hline$\geq 60$ & $3,11( \pm 0,56)$ & & $3,47( \pm 0,32)$ & & $2,85( \pm 0,63)$ & & $3,33( \pm 0,79)$ & \\
\hline \multicolumn{9}{|l|}{$\begin{array}{l}\text { Renda (em salário } \\
\text { mínimo) }\end{array}$} \\
\hline 3 a 5 & $3,00( \pm 0,65)$ & 0,361 & $3,19( \pm 0,69)$ & 0,089 & $2,69( \pm 0,66)$ & 0,197 & $3,46( \pm 0,88)$ & 0,140 \\
\hline 5 a 8 & $3,16( \pm 0,47)$ & & $3,61( \pm 0,47)$ & & $2,77( \pm 0,55)$ & & $2,96( \pm 1,09)$ & \\
\hline 8 a 11 & $3,06( \pm 0,57)$ & & $3,43( \pm 0,48)$ & & $2,96( \pm 0,43)$ & & $3,55( \pm 0,74)$ & \\
\hline \multicolumn{9}{|l|}{ Sexo } \\
\hline Feminino & $3,14( \pm 0,60)$ & 0,102 & $3,48( \pm 0,55)$ & 0,142 & $2,96( \pm 0,55)$ & 0,023 & $3,20( \pm 0,96)$ & 0,075 \\
\hline Masculino & $2,92( \pm 0,61)$ & & $3,29( \pm 0,69)$ & & $2,66( \pm 0,63)$ & & $3,52( \pm 0,82)$ & \\
\hline \multicolumn{9}{|l|}{ Estado Civil } \\
\hline Sem companheiro & $3,25( \pm 0,64)$ & 0,132 & $3,56( \pm 0,45)$ & 0,236 & $2,81( \pm 0,62)$ & 0,790 & $2,78( \pm 1,22)$ & 0,027 \\
\hline Com companheiro & $2,98( \pm 0,60)$ & & $3,34( \pm 0,65)$ & & $2,80( \pm 0,61)$ & & $3,48( \pm 0,78)$ & \\
\hline \multicolumn{9}{|l|}{$\begin{array}{l}\text { Grau de } \\
\text { preocupação }\end{array}$} \\
\hline Nenhum Pouco & $3,33( \pm 0,58)$ & 0,001 & $3,66( \pm 0,32)$ & 0,053 & $3,15( \pm 0,50)$ & 0,099 & $3,86( \pm 0,32)$ & 0,057 \\
\hline Muito pouco & $2,44( \pm 0,62)^{*}$ & & $2,75( \pm 0,99)$ & & $2,63( \pm 0,92)$ & & $2,88( \pm 0,88)$ & \\
\hline Mais ou menos & $2,90( \pm 0,64)$ & & $3,46( \pm 0,73)$ & & $2,88( \pm 0,66)$ & & $3,22( \pm 0,91)$ & \\
\hline Muito & $2,89( \pm 0,52)^{* *}$ & & $3,29( \pm 0,53)$ & & $2,64( \pm 0,56)$ & & $3,53( \pm 0,74)$ & \\
\hline Muitíssimo & $3,38( \pm 0,45)$ & & $3,50( \pm 0,44)$ & & $2,83( \pm 0,48)$ & & $3,22( \pm 1,15)$ & \\
\hline
\end{tabular}

* Muito pouco < Nenhum Pouco e Muitíssimo; ** Muito < Muitíssimo 
Comparações segundo o sexo indicaram que as mulheres focalizaram mais o Novo comeso profissional do que os homens $(p=0,023)$ e os homens apresentaram tendência a investir nos Relacionamentos Familiares $(p=0,075)$ (Tabela 4). Participantes sem companheiro(a) apresentaram menor pontuação no item Relacionamentos Familiares como fator de planejamento pós-aposentadoria $(p=0,027)$ (Tabela 4). Não houve associação entre faixa-etária, renda, tipo de carreira (docente e técnico), qualidade de vida relacionada ao trabalho e os fatores-chave para planejamento da aposentadoria.

No que se refere a sugestões dos pesquisados sobre temas para elaboração de um Programa de Preparação para a Aposentadoria, as-categorias de maior relevância foram: planejamento financeiro $(13 \%)$, legislação especifica sobre aposentadoria (11\%), entretenimento e qualidade de vida (7\%), atividades ocupacionais remuneradas após aposentadoria, empreendedorismo e apoio psicológico (6\%), promoção da saúde e projetos de vida para melhor idade (4\%), voluntariado (2\%) e PPA voltado para servidor com deficiência (1\%).

\section{DISCUSSÃO}

O perfil da população investigada compreendeu participantes com faixa etária de 50 a 55 anos representando 40,4\%; com até 15 anos para se aposentar (64,9\%), estão dentre as categorias muito ou muitíssimo preocupados com a aposentadoria, 30,9\% e $21,5 \%$, respectivamente. Essa preocupação corrobora com as discussões contemporâneas de Faganani ${ }^{1}$, Holland e Málaga ${ }^{14}$, a respeito da aposentadoria no âmbito do governo federal atual, que retrocede os direitos dos trabalhadores pelas contas da previdência. Em decorrência disso, os trabalhadores que estão próximos da aposentadoria evidenciam preocupação com o benefício no futuro.

Ao considerar a variável Qualidade de Vida no Trabalho, percebe-se maior prevalência do fator Psicológico, seguido do Pessoal, Físico e Profissional. Trata-se de um sentimento sobre o trabalho, e que esses fatores possivelmente estejam relacionados à percepção de bem-estar e satisfação pessoal. Sob esse prisma, Ferreira ${ }^{15}$ e Barretto ${ }^{16}$ traduzem que a
QVT consiste num conjunto de normas, diretrizes e práticas no âmbito das organizações de trabalho, com objetivo de promover o bem-estar e desenvolvimento pessoal dos trabalhadores.

Neste contexto, os achados de Ferreir ${ }^{15}$, Klein ${ }^{17} \mathrm{e}$ Diniz parecem indicar que a QVT pode se associar ao estabelecimento de prioridades para aposentadoria. Os profissionais que mencionaram maior importância no domínio psicológico podem ter atribuído maior importância ao fator Risco ou Sobrevivência, por este conter domínios relacionados ao bem-estarpessoal, ao passo que a maior relevância do domínio profissional pode se associar a atribuir maior importância aos relacionamentos familiares, cuja convivência pode ser desafiadora ou alvo de maior dedicação de tempo e ou investimento afetivo.

Esses resultados se associam com o estudo de Hamm et al. ${ }^{18}$ que avaliou o engajamento de pessoas adultas de meia-idade e idosos nos domínios saúde, trabalho, financas, bem-estar, relacionamentos conjugais e com crianças durante a trajetória para a aposentadoria. $\mathrm{O}$ estudo apontou que o envolvimento plausível nessas dinâmicas são fatores importantes para uma transição tranquila do curso de vida.

Essa análise se aproxima dos resultados obtidos no estudo de Klein e Diniz ${ }^{17}$ que analisou os fatores direcionadores da QVT, com base na percepção de servidores de uma organização pública, onde os fatores que influenciaram a satisfação com a QVT são as oportunidades de crescimento profissional e relacionamento com os colegas. Acrescentamse a esses fatores, os relacionamentos familiares e sociais, o lazer e os atributos do trabalho do indivíduo como decisão pela aposentadoria. Além disso, no estudo recente de Barretto ${ }^{16}$ sobre as principais fontes de bem-estar no trabalho, estão relacionadas aos aspectos das relações socioprofissionais agradáveis, realização e crescimento profissional, gestão satisfatória e sentimento de função social.

No contexto do planejamento da aposentadoria, os achados deste estudo se alinham aos de França e Menezes ${ }^{19}$ que indicou que é necessária uma segurança financeira, seguida de relações familiares, conjugal, social, de atenção à saúde, e alimentação saudável. Esses fatores relacionam-se com o estudo de Leandro-França ${ }^{20}$ sobre os aspectos de mudanças 
cognitivas, motivacionais e comportamentais; mudanças em saúde, finanças, atividades sociais e de lazer que permeiam o universo do planejamento para a aposentadoria. De acordo com Ferreira ${ }^{15}$ e Barretto $^{16}$, essas dimensões estão associadas tanto com o desenvolvimento intelectual quanto com as associações, atividades culturais e de lazer. Por outro lado, para Boehs et al. ${ }^{2}$, a percepção positiva de qualidade de vida no trabalho é um fator de intenção de continuidade da carreira na aposentadoria. Outro fator relevante deste estudo é a associação entre qualidade de vida no trabalho e fatores de planejamento da aposentaria, que evidenciou estatisticamente que os grupos estudados demostraram satisfação no domínio psicológico, pessoal e profissional. De acordo com Ferreira ${ }^{15}$, a qualidade de vida no trabalho está relacionada à satisfação geral com a vida no ambiente laboral.

Essa ideia corrobora com o estudo de Boehs et $a .^{2}$, que investigou a relação entre qualidade de vida na carreira e decisão pela aposentadoria. $\mathrm{O}$ resultado mostrou que quanto mais plena a compreensão de qualidade de vida no trabalho, maiores são os níveis de satisfação profissional, e esse fator contribui para despertar o interesse pela permanência em desenvolver atividades laborais durante a aposentadoria.

Esses dados mostram-se favoráveis no contexto de transição do trabalho para a aposentadoria, uma vez que trabalhadores que possuem uma boa qualidade de vida no trabalho dispõem de condições satisfatórias para planejar a vida pós aposentadoria, investindo em domínios que fazem sentido ao seu curso e história de vida.

Para Zanelli ${ }^{21}$ a expectativa para se aposentar tem relação com o sentido que o trabalho desempenha na vida do sujeito. Sendo assim, os aspectos psicossociais do trabalho exercem importância no processo de aposentadoria. $\mathrm{Na}$ analise de Bressan et al. ${ }^{22}$, e Argimon $^{23}$, somam-se a esse fator, as condições satisfatórias de saúde física, psicológica, atividades de lazer e social, relacionamento familiar e laços de amizades. Esses recursos funcionam como mecanismos importantes, pois influenciam na qualidade de vida dos aposentados.
Outro fator que se relaciona nesse contexto foi indicado na pesquisa de França e Carneiro ${ }^{13}$ com executivos, em que apontou que os trabalhadores mais jovens estavam favoráveis a permanecer no trabalho por mais tempo e, assim, adiar a chegada da aposentadoria, ao contrário dos trabalhadores mais velhos, que vislumbravam o período da inatividade para se dedicarem à família e a atividades prazerosas.

No presente estudo chamou a atenção a relação entre preocupação com a aposentadoria e o fator bem-estar pessoal e social como um dos elementos para o planejamento da aposentadoria: Profissionais que referiam estar Muito pouco preocupados tiveram pontuações menores nesse domínio do que os que referiram Nenhum pouco e muitíssimo; e profissionais Muito preocupados apresentaram menor pontuação do que aqueles que referiram Muitíssimo. A relação entre essas variáveis deve ser melhor explorada, tendo em vista que a preocupação pode denotar a ansiedade e ao mesmo tempo a previsão ou expectativa sobre a aposentadoria.

É possível que os resultados do presente estudo estejam relacionados ao elevado nível de escolaridade da amostra, e também aos papéis de gênero socialmente aceitos: homens, à vida dedicada ao trabalho; mulheres, à jornada dupla ou tripla relacionada à orquestração dos papéis no âmbito do trabalho e da família. Referindo-se ao papel de gênero, o estudo Bohes et al. ${ }^{2}$, apontou que mulheres que têm empregos de alta responsabilidade, com elevado nível de escolaridade e salários, não se adequam ao padrão básico atribuído à mulher pelas atividades domésticas, sendo expectável que atribuam maior valor ao papel profissional. Desta forma, na ausência do trabalho, as mulheres possuiriam maior flexibilidade para se engajar em novas atividades, selecionando recursos e projetos que se coadunam com variáveis relacionadas ao desenvolvimento pessoal ou a projetos que não conseguiram realizar em outras etapas do curso de vida. Davidson et al. ${ }^{24}$, relata que as mulheres consideraram sua satisfação com seus papéis pessoais e profissionais aliado aos desejos pessoais com as exigências sociais, conciliando o sucesso profissional e financeiro, ao mesmo tempo em que desempenha o papel materno. 
No que se refere aos temas para a promoção de um PPA, os itens mais relatados, conforme as respostas dos participantes, foram: "planejamento financeiro, seguidos de legislação específica sobre aposentadoria, entretenimento e qualidade de vida, atividades ocupacionais remuneradas após aposentadoria, empreendedorismo e apoio, promoção da saúde, projetos de vida para velhice, voluntariado" e, por fim, o "PPA voltado para servidor com deficiência". Destaca-se aqui que, com a aposentadoria, muitos trabalhadores sofrem decréscimo de seus salários, seguidos pelo aumento de gastos com a saúde e pelas transições que acompanham essa fase da vida, como a saída dos filhos de casa, a diminuição da rede de contatos sociais e os ajustes com a ocupação do tempo livre. $\mathrm{O}$ interesse por aspectos da legislação pode ancorar-se pelas mudanças recentes das leis que regulam a aposentadoria, iniciadas em 2016 e em vigor com a Reforma da Previdência promulgada no ano de 2019. Neste sentido, Nascimento e Polia ${ }^{6}$ revelam as principais percepções para aposentadoria de docentes de uma Universidade Federal, que alterou a perspectiva da aposentadoria para alguns professores, demonstrado preocupação e ansiedade com relação ao seu futuro, devido as inseguranças da última reforma previdenciária.

Nesse contexto, cabe um breve resumo da Reforma da Previdência no Brasil, com destaque para as últimas modificações, conforme percepções de Fagnani ${ }^{1}$, Nascimento, Polia ${ }^{6}$ e Aguiar ${ }^{25}$. Assim, a primeira mudança ocorrida no sistema previdenciário brasileiro foi em 1991, na era Collor, onde o cálculo do valor do benefício passou a levar em conta a correção monetária. Posteriormente, em 2003, no governo de Lula, com foco no funcionalismo público, a reforma dificultou o acesso dos servidores à aposentadoria. Em 2015, no governo de Rousseff, foi sancionado um projeto de lei que criou um novo cálculo previdenciário, a fórmula $85 / 95$. O governo Temer tentou uma reforma com a PEC 287/2016, mas não foi aprovada. Por sua vez, a reforma de Bolsonaro, com a PEC 6/2019, objetivou conter o deficit nas contas públicas, trocando o modelo previdenciário de repartição para o de capitalização. Essa reforma mudou as regras da aposentadoria, fixando idade mínima para se aposentar e acréscimo no tempo de contribuição.
Essa síntese mostra que o sistema previdenciário no Brasil é frágil, e que outras reformas poderão surgir de acordo com interesses do governo e ou pela pressão da sociedade. Neste cenário, sustenta Aguiar $^{25}$ que a Reforma da Previdência força o trabalhador a permanecer por mais tempo na ativa, sem considerar as limitações humanas provocadas pelo processo de envelhecimento, em que as transformações derivadas da senescência podem afetar a realização das atividades laborais, e pelo próprio desgaste excessivo do trabalhador ao longo dos anos com suas tarefas funcionais.

Apesar dos achados destacarem a associação entre qualidade de vida no trabalho, sexo, estado civil e fatores para o planejamento da aposentadoria, é importante mencionar que, durante a aplicação dos questionários, observou-se que alguns professores e técnicos administrativos ainda não tinham refletido sobre o planejamento da aposentadoria.

Diante dos apontamentos, sugere-se para os próximos estudos um comparativo entre carreiras de servidores, bem como a elaboração de estudos em outros contextos, para que a temática do planejamento da aposentadoria ultrapasse o campo público, despertando, também, as organizações privadas para o desenvolvimento de programas de preparação para a aposentadoria de seus colaboradores.

\section{CONCLUSÃO}

O planejamento para aposentadoria parece ser influenciado pela qualidade de vida relacionada ao trabalho e por variáveis como sexo e estado conjugal. O estudo permitiu explorar o planejamento da aposentadoria, fornecendo contribuições de temáticas para que a organização desenvolva em um Programa de Preparação para a Aposentadoria, de acordo com as sugestões dos servidores investigados.

A contribuição social desta pesquisa possibilitou aos sujeitos investigados maior entendimento e reflexão sobre o universo da aposentadoria, bem como para o campo científico, pois demonstrou as inquietações da população investigada e apresentou 
estratégias que favoreçam a preparação e o planejamento para o enfrentamento dos desafios da humanidade nos aspectos que perpassam essa temática; em um diálogo com as diretrizes do sistema previdenciário brasileiro que, no contexto de reforma, alterou as regras de acesso aos benefícios previdenciários, tornando a aposentadoria para muitos trabalhadores num universo de incertezas, causando impactos principalmente na população idosa.

\section{REFERÊNCIAS}

1. Fagnani E. O debate desonesto: subsídios para a ação social e parlamentar: pontos inaceitáveis da Reforma de Bolsonaro. São Paulo: Contracorrente. 2019. p. 41-143.

2. Boehs STM, Bardagi MP, Silva N. Trabalho, aposentadoria e satisfação de vida em aposentados de uma multinacional. Rev Psicol Organ Trab [Internet]. 2019 [acesso em 08 mar 2019]:19(3):65361. Disponível em: http://dx.doi.org/10.17652/ rpot/2019.3.16310.

3. Corrêa DA, Oswaldo YC, Spers VER, Graziano GO, Andrade SI, Santos MR. Qualidade de vida no trabalho: uma análise crítica da produção bibliográfica brasileira na área de gestão. In: Resumo do $2 \mathrm{e}$ Congresso Transformare de Paris;19-20 mars 2012; Paris. França; 2012.

4. Albornoz S. O que é trabalho. $8^{a}$ ed. São Paulo: Brasiliense; 2008. Cap. 7: O que a palavra trabalho significa. p. 7-43. (Coleção Primeiros Passos; 171).

5. Pós. In: DICIO - Dicionário Online de Português, definições e significados de mais de 400 mil palavras. Todas as palavras de A a Z [Internet]. Porto: 7Graus; 2020 [acesso em 30 jul. 2020]. Disponível em: https:// www.dicio.com.br/pos/.

6. Nascimento PDM, Polia AA. Planos para o futuro: uma análise da perspectiva ocupacional de professores universitários para o período da aposentadoria. Cad Bras Ter Ocup. 2019;27(2):1-10. Disponível em: http://dx.doi.org/10.4322/2526-8910.ctoao1647.

7. Soares DHP, Costa AB, Rosa AM, Oliveira MLS. Aposenta-ção: programa de preparação para a aposentadoria. Rev Estud Interdiscipl Envelhec. 2017;12(6):143-61. Disponível em: https://seer.ufrgs. br/RevEnvelhecer/article/download/4984/2853.

8. Menezes GS, França LH. Preditores da decisão da aposentadoria por servidores públicos federais. Rev Psicol Organ Trab. 2012;12(3):1-10. Disponível em: http://pepsic.bvsalud.org/scielo.php?script=sci_ arttext\&pid=S1984-66572012000300006.
$\mathrm{Na}$ agenda do planejamento da aposentadoria, as instituições devem incorporar a complexidade dos elementos relacionadas ao envelhecimento, fomentando ações intergeracionais; bem como devem promover o acesso à reflexões que contribuem para que os servidores percebam a aposentadoria como um processo natural.

Editado por: Yan Nogueira Leite de Freitas

9. Rafalski JC, Andrade ALA. Planejamento da aposentadoria: adaptação brasileira da PRePS e influência de estilos de tomada de decisão. Rev Psic Organ Trab.. 2016;16(1):36-45. Disponível em: http://pepsic.bvsalud.org/scielo.php?script=sci_ abstract\&pid=S1984-66572016000100004\&lng=pt.

10. Froidevaux ABI, Maggiori C. Planejamento de aposentadoria: como lidar com diferentes trajetórias de ajuste? In: Ertelt BJ, Scharpf M, editores. Guia de carreira para trabalhadores mais velhos. Nova York: Peter Lang; 2017; p. 25-53.

11. França LHF, Hershey DA. Preparação financeira para a aposentadoria no Brasil: um Teste Intercultural do Modelo Interdisciplinar de Planejamento Financeiro. Rev J Cross Cult Gerontol. 2018;(33)4364. Disponível em: https://www.springer.com/ journal/10823.

12. Cheremeta M, Pedroso B, Pilatti LA, Kovaleski JL. Construção da versão abreviada do QWLQ-78: um instrumento de avaliação da qualidade de vida no trabalho. Rev Bras Qual Vida. 2011;3(1):1-15. Disponível em: http://dx.doi.org/10.3895/S217508582011000100001 .

13. França LHFP, Carneiro VL. Programas de preparação para a aposentadoria: um estudo com trabalhadores mais velhos em Resende. Rev Bras Geriatr Gerontol. 2009;12(3):429-47. Disponível em: https://doi. org/10.1590/1809-9823.2009.00010.

14. Holland M, Málaga T. Previdência social no Brasil: propostas para uma reforma de longo prazo [Internet]. Brasília, DF: Fundação Getúlio Vargas 2018 [acesso em 11 mar. 2020]. Disponível em: http://bibliotecadigital.fgv.br/dspace/bitstream/ handle/10438/24784/TD $\% 20487 \% 20-\% 20$ Marcio $\% 20$ Holland.pdf?sequence $=1 \&$ is Allowed $=y$.

15. Ferreira MC. Qualidade de vida no trabalho: uma abordagem centrada no olhar dos trabalhadores. Brasília, DF: Paralelo 15; 2016. p. 125-92. 
16. Barretto RM. Sentir que meu trabalho pode impactar positivamente a vida dos cidadãos: práticas gerenciais e percepções de qualidade de vida no trabalho, bemestar e mal-estar no trabalho do gestor público federal [dissertação Internet]. Brasília, DF: Universidade de Brasília; 2018 [acesso em 22 fev. 2018]. Disponível em: https://repositorio.unb.br/handle/10482/32422.

17. Klein LL, Lemos RB, Diniz PBA, Beltrone G. Qualidade de vida no serviço público: uma avaliação em uma instituição de ensino superior. REAd. Rev Eletrônica Adm. 2017;23(Esp.):1-10. Disponível em: https://doi.org/10.1590/1413-2311.158.59511.

18. Hamm JM, Heckhausen J, Shane J, Infurna FJ, Lachman ME. Engagement with six major domains of life during the transition to retirement: Stability and change for better or worse. Psychol Aging. 2019;34(3):441-56. Disponível em: https://doi. org/10.1037/pag0000343 .

19. França LHFP, Menezes GS, Bendassolli PF, Macedo LSS. Aposentar-se ou continuar trabalhando? o que influencia essa decisão? Psicol Ciênc prof. 2013;33(3):548-63. Disponível em: http://dx.doi. org/10.1590/S1414-98932013000300004 .
20. Leandro-França C, Murta SG, Hershey DA, Martins BL. Evaluation of retirement planning programs: a qualitative analysis of methodologies and efficacy. Educ Gerontol. 2016;42(7):497-512. Disponível em: https://doi.org/10.1080/03601277.2016.1156380.

21. Zanelli JC, Silva N, Soares DHP. Orientação para aposentadoria nas organizações de trabalho: construção de projetos para o pós-carreira. Porto Alegre: Artmed; 2013. p. 27-63.

22. Bressan MALC, Mafra CT, França LHFP, Melo MSS, Loretto MDS. Bem-estar na aposentadoria: o que isto significa para os servidores públicos federais? Rev Bras Geriatr Gerontol. 2013;16(2):259-72. Disponível em: http://dx.doi.org/10.1590/S1809-98232013000200006.

23. Argimon IIL, Esteves CS, Wendt GW. Ciclo vital: perspectivas contemporâneas em avaliação e intervenção. Porto Alegre: EDIPUCRS; 2015.

24. Davidson S, Major PW, Carlos AM, Keenan L. Women in Orthodontics and work-family balance: challenges and strategies. J Can Dent Assoc. 2012;78(61):1-9. Disponível em: https://jcda.ca/article/c61.

25. Aguiar VJP. História da Previdência Social Brasileira. Politize [Internet]. 2018 [acesso em 23 fev. 2020]. Disponível em: https://www.politize.com.br/historiada-previdencia-no-brasil/. 